\title{
БАРЬЕРЫ ФОРМИРОВАНИЯ ГОТОВНОСТИ СТУ ДЕНТОК ИНДУСТРИАЛЬНЫХ КОЛЯЕДЖЕЙ РОССИИ, КИТАЯ И ИРАНА К РАБОТЕ В ОРГАНИЗАЦИОННЫХ УСЛОВИЯХ ИННОВАЦИОННЫХ КОМПАНИЙ
}

\begin{abstract}
А. Н. Захарова, З. Х.-М. Саралиева, З. Гадбеджи
Национальный исследовательский Нижегородский государственный университет им. Н. И. Лобачевского, г. Нижний Новгород, Россия, zara@fsn.unn.ru

Представлены результаты эмпирического исследования организационной социализации студенток российских, китайских и иранских индустриальных колледжей для работы в современных инновационных компаниях. Выявлена зависимость организационной культуры колледжа от экономической ситуации в стране и роль организационной культуры в формировании субъективного благополучия студенток. Российские студентки чувствуют субъективный дискомфорт, нехватку эмоциональной поддержки в процессе получения образования, для них характерно неполное знание требований современных организационных условий и нежелание работать на инновационных предприятиях, их вовлеченность в учебу/труд и активность зависят от степени удовольствия, которое они получают в учебном и трудовом процессе. Показана необходимость программ упреждающей организационной социализации для системы специального среднего образования с учетом возрастной и гендерной специфики.
\end{abstract}

Ключевые слова: индустрия 4.0, индустриальные колледжи, студентки, рынок труда, стереотипы, ценности, организационная культура, отношение к труду, организационная социализация.

\section{BARRIERS ON THE WAY OF FEMALE STUDENTS OF INDUSTRIAL COLLEGES OF RUSSIA, CHINA AND IRAN TO BE READY TO WORK IN ORGANIZATIONAL CONDITIONS OF INNOVATIVE COMPANIES}

\author{
L. N. Zakharova, Z. H.-M. Saraliyeva, Z. Gadbegi \\ National Research Lobachevsky State University of Nizhny Novgorod, \\ Nizhny Novgorod, Russian Federation, zara@fsn.unn.ru
}

The paper presents the results of empirical research into organizational socialization of students from Russian, Chinese and Iranian industrial colleges who are required to work in modern innovative companies. The research underlines the pivotal role of organizational culture as a socio-psychological context of the educational process and a key factor in the emerging attitude

(C) Захарова Л. Н., Саралиева 3. Х.-М., Гадбеджи 3., 2021 
to education and work. The research has revealed specifics of girls' subjective well-being in organizational cultures of different types as well as organizational, information and emotional barriers which negatively affect their readiness to work in innovative companies. For instance, Russian students feel subjective discomfort, lack of emotional support during education; incomplete knowledge of the requirements of modern organizational conditions, disbelief and unwillingness to work in an innovative company are typical of them; their involvement and activities depend on the pleasure they receive or do not receive while studying or working. Chinese women are usually confident of finding jobs in innovative enterprises and they are satisfied with the quality of their professional training and the balanced organizational culture of their colleges; they demonstrate limited involvement and activities — the characteristics required by their employers or educational bodies. Conservative organizational conditions in the hierarchy prevail in Iranian colleges. They discourage girls from learning and working which adds to disbelief in positive economic changes. Thus, the paper shows that organizational culture of colleges largely depends on particular social and economic situation in the country, underlines the importance of organizational culture in forming subjective well-being of female students. The paper also reveals how emotional factors can affect Russian female students' attitude to educational and labor activity. In conclusion, importance of proactive organizational socialization of girls, the need to develop and implement socialization programs that take into account gender identity of female students and typical characteristics of their life paths are underlined.

Key words: industry 4.0, industrial colleges, girl students, labor market, stereotypes, values, organizational culture, attitude to work, organizational socialization.

Стремительное наступление нового технологического уклада индустрии 4.0 меняет рынок труда, значительно усложняет положение на нем людей молодого и старшего возраста, особенно женщин. Молодые женщины, прежде всего выбравшие профессию, которая традиционно ассоциируется в общественном сознании с мужской сферой деятельности, закономерно испытывают трудности на рынке труда. Это относится ко всем уровням образования, в том числе и к среднему специальному.

Чтобы получить хорошую работу в инновационной компании, нужно обладать не только профессиональными функциональными компетенциями, но и особыми социально-психологическими. Ключевыми психологическими характеристиками работников, востребованными в индустрии 4.0, являются готовность к принятию технологических и управленческих инноваций, личностная вовлеченность в трудовой процесс, ответственность и инициативность в обучении и самообучении [Квачев, Юдина, 2017]. Баланс в подготовке специалистов в системе специального профессионального образования (СПО) пока смещен в пользу профессиональных умений [Нагимова, Фахретдинова, 2019]. В результате уровень безработицы среди выпускников системы СПО примерно в 1,5 раза выше среднего по стране, около 70 \% работают не по полученной профессии или специальности и занимают преимущественно рабочие места, требующие меньшего уровня квалификации, чем приобретенный ими в результате обучения, и с меньшей зарплатой, чем та, на которую они могли бы претендовать [Дудырев и др., 2019: 129, 131]. Рассчитывать на эффективную спонтанную социализацию в период практики не приходится: в стране не так много предприятий, успешно вошедших в новый экономический уклад индустрии 4.0, имеющих 
специфические модели управления, организационной структуры и организационной культуры [Горобец, 2015; Волков, 2020; Захарова и др., 2020].

Проблема организационной социализации имеет довольно большую историю. И как правило, она решалась в конкретной компании введением нового работника в специфику ее организационных условий [Van Maanen, 1978]. С усложнением организационных условий и ростом издержек компаний на социализацию сотрудников акцент смещался в сторону упреждающей организационной социализации, которая может реализоваться и в образовательном учреждении [Fetherston, 2017]. Упреждающая организационная социализация девушек, выбравших технические специальности, еще более актуальна. Работодатель должен убедиться как можно раньше в их профессиональной компетентности и организационной социализированности, поскольку выпускницы колледжей относятся к той категории сотрудников, которые в силу возраста и гендерной принадлежности склонны к раннему созданию семьи, рождению и воспитанию детей.

Выбор технической специальности девочками не легок, поскольку затрудняется устойчивыми стереотипами относительно их способностей к работе. Однако нередко поддержка, оказываемая учителями в школе ориентирует способных девочек на выбор технических профессий. Девушки, избравшие техническое образование, часто недовольны обучением, реже предпочитают работать по полученной специальности, поскольку условия обучения и трудовой деятельности, стереотипы коллег и менеджеров делают их трудовую жизнь лишенной субъективного благополучия [Ellis et al., 2016].

Женщинам, занятым в технической сфере и заботящимся о семье, трудно достичь уровня производительности мужчин. Технологии в технической сфере развиваются очень быстро, и если женщина не обладает навыками самоорганизации и самообучения, она теряет квалификацию, когда уходит в отпуск по беременности или берет больничные по уходу за ребенком [Савинская, Лебедева, 2020]. Перерыв в профессиональной деятельности в условиях стремительного развития и внедрения новых технологий, появление внетрудовых интересов, утрата связи с трудовым коллективом могут стать непреодолимой преградой для возвращения на рабочее место и повторной организационной социализации.

Уделяется ли достаточное внимание в колледжах решению проблемы организационной социализации с учетом гендерного аспекта подготовки? Ответ на этот вопрос требует изучения.

Процесс организационной социализации вполне обоснованно можно рассматривать как социальное действие, интерактивный процесс, детерминированный общекультурными установками населения, организационной культурой компании, личностными установками самого субъекта социального действия и его психофизиологическими качествами [Парсонс, 2000]. Основная роль в системе детерминации организационной социализации принадлежит организационной культуре (ОК) компании, которая содержит ценности организационного развития, характерные для критической массы персонала, и соответствующие этим ценностям модели поведения [Brettel et al., 2015]. Менеджмент, воздействуя на ОК, может существенно смягчить влияние национальной культуры, меняющейся медленнее, чем экономический уклад, изменить отношение сотрудников 
к трудовой деятельности, повышая их субъективное благополучие через профилактику стресса, вызываемого организационными изменениями, снижая влияние внедрения инноваций на психофизиологическом уровне.

Исследование организационной социализации девушек в колледжах целесообразно проводить с применением кросс-культурного подхода, позволяющего сравнивать специфику упреждающей социализации в различных национальных и соответствующих им организационных культурах. Особый интерес представляет организационная социализация в странах, имеющих одинаковые экономические задачи вхождения в индустрию 4.0, но различающихся своей результативностью, отраженной в глобальных индексах инновационности. Для сравнительного анализа организационной социализации в российских колледжах взяты колледжи Китайской Народной Республики и Исламской Республики Иран.

Китайская экономика успешно наращивает уровень инновационности, ее рейтинг в глобальном индексе инновационности постоянно повышается, сегодня это 17-е место. В китайских компаниях реализуются программы организационной социализации, направленные на развитие инновационности сотрудников [Завьялова и др., 2018].

В Иране в условиях многолетних санкций создана экономика, напоминающая экономику военного времени с жестким административным управлением [Мамедова, 2015], страна стабильно занимает 61-е место в рейтинге инновационности.

Россия, большая часть населения которой до сих пор не адаптировалась к требованиям и условиям рыночной экономики, существенно отстает в управлении компаниями [Внутских, Комаров, 2019]. Страна занимает 46-е место в рейтинге инновационности, что, безусловно, не может считаться достойным показателем [Global Innovation Index..., 2019].

Гипотезой проведенного эмпирического исследования было предположение о том, что организационная культура колледжей стран, экономика которых различается уровнем вовлеченности в инновационные процессы, обладает специфическим потенциалом организационной социализации студенток для трудовой деятельности на инновационных предприятиях и по-разному влияет на важнейшие характеристики отношения к учебе и труду, востребованные индустрией 4.0.

Респондентами являлись студентки индустриальных колледжей России и Китая (Нижний Новгород и Гуанси - типичные для своих стран города индустриального кластера), иранские студентки программы «кардани» (г. Тегеран), что соответствует возрастной группе, целям и содержанию обучения в российских и китайских колледжах. В исследовании приняли участие 315 девушек и 92 преподавателя примерно в равных пропорциях по странам.

Метод диагностики организационной культуры и ценностных организационно-культурных предпочтений (OCAI) К. Камерона и Р. Куинна [Cameron, Quinn, 2011] применен при определении уровня адаптации к образовательным учреждениям. Представления студенток об организационных условиях будущего рабочего места и предприятия, эффективного в современных условиях, выявлены с помощью дополнительных вопросов. работать?

1. На предприятии с какими организационными условиями вы бы хотели 
2. Какие условия будут, скорее всего, на том предприятии, куда вы придете работать после окончания колледжа?

3. Предприятие с какими организационными условиями будет наиболее эффективно в современной экономике?

Метод WorkBAT [Spence, Robbins, 1992] позволил выявить характеристики отношения к учебе и труду, наиболее востребованные индустрией 4.0. Для статистической обработки данных использованы непараметрические критерии Манна - Уитни и Вилкоксона.

\section{Результаты исследования и их анализ}

Для понимания уровня субъективного благополучия студенток, выбравших профессии, не согласующиеся с традиционными взглядами на место женщин в разделении труда, необходимо выявить, насколько обусловливают данный уровень организационные условия колледжей (табл. 1).

Таблицуа 1

Организационная культура в колледжах России, Китая и Ирана, организационно-культурные предпочтения студенток и преподавателей

\begin{tabular}{|c|c|c|c|c|c|c|c|c|c|c|c|c|c|}
\hline \multirow{3}{*}{ Страна } & \multirow{3}{*}{$\begin{array}{c}\text { Категория } \\
\text { респондентов }\end{array}$} & \multicolumn{12}{|c|}{ Компонент организационной культуры, \% } \\
\hline & & \multicolumn{3}{|c|}{$\mathrm{K}$} & \multicolumn{3}{|c|}{ A } & \multicolumn{3}{|c|}{ Д } & \multicolumn{3}{|c|}{ И } \\
\hline & & $\Phi$ & $\Pi$ & $\mathrm{W}$ & $\Phi$ & $\Pi$ & $\mathrm{W}$ & $\Phi$ & $\Pi$ & $\mathrm{W}$ & $\Phi$ & $\Pi$ & $\mathrm{W}$ \\
\hline \multirow{3}{*}{ Россия } & Девушки & 25 & 37 & $* *$ & 19 & 17 & - & 27 & 24 & $*$ & 31 & 23 & $* *$ \\
\hline & Преподаватели & 28 & 33 & $*$ & 24 & 29 & $*$ & 24 & 18 & $*$ & 33 & 20 & $*$ \\
\hline & $\mathrm{U}$ & $*$ & $*$ & & $*$ & $*$ & & - & $*$ & & - & - & \\
\hline \multirow{3}{*}{ Китай } & Девушки & 27 & 28 & - & 22 & 23 & - & 24 & 23 & - & 27 & 27 & - \\
\hline & Преподаватели & 27 & 27 & - & 22 & 22 & - & 25 & 24 & - & 26 & 27 & - \\
\hline & $\mathrm{U}$ & - & - & & - & - & & - & - & & - & - & \\
\hline \multirow{3}{*}{ Иран } & Девушки & 21 & 33 & $* *$ & 14 & 29 & $* *$ & 24 & 11 & $* *$ & 41 & 27 & $* *$ \\
\hline & Преподаватели & 27 & 26 & - & 17 & 17 & - & 23 & 23 & - & 33 & 34 & - \\
\hline & $\mathrm{U}$ & $*$ & $* *$ & & $*$ & $* *$ & & - & $* *$ & & $*$ & $*$ & \\
\hline
\end{tabular}

Примечания. К - клановый, А - адхократический (инновационный), Д - деловой (рыночный), И - иерархический; Ф - фактическая выраженность компонента ОК, П - предпочтительная выраженность; U - статистическая значимость различий по критерию Манна - Уитни, $\mathrm{W}-$ по критерию Вилкоксона; * $-\mathrm{p} \leq 0.05 ; * *-\mathrm{p} \leq 0.01$; - - статистически значимые различия отсутствуют.

Можно видеть, что россиянки и иранки испытывают серьезный дефицит ценности отношений в организационной культуре колледжей, хотят изменить это положение, существенно усилив клановую составляющую ОК: россиянки с 25 до $37 \%$, иранки с 21 до $33 \%(\mathrm{p} \leq 0.01)$. И в российских, и в иранских колледжах преподаватели не понимают эмоционального состояния девушек, полагая, что клановая составляющая и так представлена вполне достаточно, в значительно большей мере, чем это чувствуют девушки. Но нужно учитывать, что именно 
в клановой составляющей эмоциональный компонент восприятия ситуации проявляется наиболее отчетливо (межличностные связи, поддержка, психологическая защита). Девушки лишены значимого для них чувства субъективного благополучия, организационные условия представляются им очень суровыми.

Иерархический компонент ОК занимает доминирующее место. У россиянок его присутствие оценивается в $31 \%$, а в оценках иранок он достигает $41 \%$. И те и другие желают снизить его: россиянки до $23 \%$, иранки до $27 \%$. Как и в случае с клановым компонентом, величина изменения статистически значима: $\mathrm{p} \leq 0.01$. Преподаватели и в отношении иерархии имеют мнение, не совпадающее с мнением студенток. Российские преподаватели полагают, что уровень иерархии следовало бы уменьшить, но ненамного, а иранские преподаватели считают, что имеющийся уровень иерархии в $33 \%$ должен оставаться таким с небольшим статистически незначимым вектором усиления.

Студентки тяжело переживают организационные условия колледжей и не находят поддержки у преподавателей. Расхождения между российскими и иранскими девушками, тем не менее, есть, они касаются более всего современных трендов в экономике - их инновационно-рыночной составляющей. Иранки понимают, насколько сильно они отстают в своей инновационности. Ее уровень следует увеличить с 14 до $29 \%, \mathrm{p} \leq 0.01$, но у них нет понимания связи инновационного и рыночного компонентов организационных условий (делового - в системе образования): рост инновационности они увязывают с необходимостью снижения делового компонента ОК. У россиянок принципиально другое отношение к этим компонентам ОК. Уровень инновационности (19\%) им кажется довольно высоким, они предпочли бы его понизить. Показатель делового компонента им, как и иранкам, хотелось бы уменьшить, но не в такой степени: с 27 до $24 \%, \mathrm{p} \leq 0.05$.

Эти данные свидетельствуют о том, что студентки индустриальных российских и иранских колледжей желали бы работать в условиях комфортных межличностных отношений, не придавая особого значения регламентам производственных процессов, что закономерно ведет к снижению эффективности трудовой деятельности. И это не проблема девушек, а проблема образовательного процесса, вынуждающего их желать такого смягчения организационных условий, которое даст им чувство субъективного благополучия.

Иная ситуация в китайской образовательной практике. В китайских колледжах наблюдается поразительное единство в оценках ОК студенток и преподавателей. ОК гармонична с определенным превышением средних показателей по клановому и иерархическому компонентам, что видится весьма позитивным. Представленность кланового компонента близка к его представленности в иранских и российских колледжах, но китаянки не обнаруживают желания усиливать данный компонент. Следовательно, они чувствуют себя вполне комфортно и готовятся к работе в условиях, требующих максимального соблюдения регламентов производственных процессов. И это при высоком уровне инновационности (22-23\%) и деловом климате $(24-23 \%)$.

Данные таблицы 2 показывают, насколько девушки и преподаватели понимают требования организационных условий современных эффективных компаний и в каких условиях, скорее всего, работать девушкам по окончании колледжей. 
Представления студенток и преподавателей колледжей России, Китая, Ирана об организационных условиях современных предприятий

\begin{tabular}{|c|c|c|c|c|c|c|c|c|c|c|c|c|c|}
\hline \multirow{3}{*}{ Страна } & \multirow{3}{*}{$\begin{array}{c}\text { Категория } \\
\text { респондентов }\end{array}$} & \multicolumn{12}{|c|}{ Компонент организационной культуры, \% } \\
\hline & & \multicolumn{3}{|c|}{ K } & \multicolumn{3}{|c|}{ A } & \multicolumn{3}{|c|}{ Д } & \multicolumn{3}{|c|}{ И } \\
\hline & & $\mathrm{Pe}$ & Эф & $\mathrm{W}$ & $\mathrm{Pe}$ & Эф & $\mathrm{W}$ & $\mathrm{Pe}$ & Эф & $\mathrm{W}$ & $\mathrm{Pe}$ & Эф & $\mathrm{W}$ \\
\hline \multirow{3}{*}{ Россия } & Девушки & 32 & 32 & - & 21 & 23 & - & 21 & 26 & $*$ & 26 & 19 & $* *$ \\
\hline & Преподаватели & 31 & 28 & $\mathrm{~T}$ & 21 & 26 & $*$ & 19 & 22 & $\mathrm{~T}$ & 28 & 24 & $*$ \\
\hline & $\mathrm{U}$ & - & $*$ & & - & $\mathrm{T}$ & & $*$ & $*$ & & $*$ & $*$ & \\
\hline \multirow{3}{*}{ Китай } & Девушки & 27 & 28 & - & 22 & 22 & - & 25 & 24 & - & 26 & 27 & - \\
\hline & Преподаватели & 28 & 28 & - & 22 & 21 & - & 24 & 25 & - & 26 & 26 & - \\
\hline & $\mathrm{U}$ & - & - & & - & - & & - & - & & - & - & \\
\hline \multirow{3}{*}{ Иран } & Девушки & 22 & 26 & $*$ & 20 & 24 & $*$ & 24 & 20 & $*$ & 36 & 30 & $*$ \\
\hline & Преподаватели & 26 & 26 & - & 17 & 18 & - & 23 & 22 & - & 34 & 33 & - \\
\hline & $\mathrm{U}$ & $*$ & - & & $*$ & $* *$ & & - & - & & - & - & \\
\hline
\end{tabular}

Примечания. Ре - представления об ОК предприятия - будущего места работы, Эф - представления об ОК современного эффективного предприятия; Т — тенденция (см. также обозначения к табл. 1).

Россиянки полагают, что им придется работать на предприятии, где модель ОК кланово-иерархическая, что в целом соответствует особенностям организационных отношений в ординарных, неинновационных, компаниях. Хотя, безусловно, модель ОК будет не кланово-иерархическая, а иерархическиклановая. Но девушкам, по-видимому, хочется верить, что им нигде не будет так плохо, как в колледже: 32 \% клановых ценностей - это меньше, чем бы им хотелось, но существенно больше, чем в колледже. Организационные условия, по их представлениям, на эффективных современных предприятиях иные, чем на тех, на которые они придут работать, но не по значимым для девушек характеристикам. Эффективным предприятиям, считают они, тоже свойственна абсолютная доминанта кланового компонента, существенно меньшая иерархичность, меньше даже того уровня, который они хотели бы иметь в колледжах. Но ни по инновационному, ни по деловому компоненту они не отмечают существенных различий между будущим местом работы и инновационной компанией, хотя инновационность в эффективной компании все же выше, причем выше той, какую они хотели бы иметь. Можно вполне обоснованно полагать, что у российских студенток индустриальных колледжей довольно смутное представление об организационных условиях современных эффективных предприятий и они чувствуют близость ОК колледжей к ОК тех предприятий, куда они придут работать, надеясь на приоритет кланового компонента. Российские преподаватели в целом адекватно оценивают специфику организационных условий современных эффективных компаний, но различия с предприятиями - будущими местами работы выпускниц проявляются неярко. Видимо, преподаватели хотят показать, что выпускницы будут работать не на самых эффективных, но все же достаточно инновационных предприятиях. 
Иранские студентки оценивают и будущие места работы, и организационные условия эффективных компаний более реалистично. Они полагают, что придут работать в компании с иерархически-деловой ОК, клановый компонент которой существенно менее выражен, чем им хотелось бы, — такой же, как в колледже. Заслуживает внимания следующий факт: иранские девушки считают, что на инновационных предприятиях значимость инновационного компонента ОК гораздо ниже, чем бы им хотелось (24 против 29 \%). То есть девушки оценивают уровень инновационности иранских компаний как существенно более низкий, чем мировой. Тем не менее уровень иерархичности современных эффективных компаний они определяют как высокий, почти такой же, как уровень китайских компаний. Их оценки близки к оценкам китаянок. Это интересный факт, поскольку преподаватели студенток настроены очень консервативно: они оценивают уровень инновационности компаний, в том числе и эффективных, как самый низкий. По-видимому, девушки черпают сведения о развитии мировой и иранской экономики не от преподавателей, а из других источников. В целом иранские студентки не верят, что придут работать на современное эффективное предприятие: по всем показателям различия между реальным и эффективным предприятием статистически значимы ( $\mathrm{p} \leq 0.05)$, и позиция преподавателей усиливает безнадежность.

Оценки организационных условий в китайских колледжах, компаниях, куда придут выпускницы, и в современных эффективных компаниях не различаются у студенток и преподавателей, т. е. китаянки уверены, что придут работать на инновационные предприятия, и в колледжах их готовят к работе именно в таких компаниях.

В таблице 3 приведены данные об отношении к учебе и труду студенток, обучающихся в разных организационных условиях и имеющих разные надежды на условия будущей трудовой деятельности.

Таблица 3

Отношение к учебе и труду студенток китайских, российских и иранских индустриальных колледжей

\begin{tabular}{|c|c|c|c|c|c|c|}
\hline \multirow{2}{*}{ Страна } & \multicolumn{3}{|c|}{ Позитивные показатели } & \multicolumn{3}{|c|}{ Негативные показатели } \\
\hline & Вовлеченность & Активность & Удовольствие & Невовлеченность & Пассивность & Отвращение \\
\hline Россия & 3.03 & 2.76 & 2.84 & 2.25 & 3.13 & 2.83 \\
\hline Китай & 2.62 & 2.46 & 2.64 & 2.39 & 2.81 & 2.65 \\
\hline Иран & 2.76 & 2.61 & 1.94 & 3.24 & 3.55 & 3.38 \\
\hline $\begin{array}{l}\text { Статистическая } \\
\text { значимость } \\
\text { различий: } \\
\text { Россия - Китай }\end{array}$ & $*$ & $*$ & - & $*$ & - & - \\
\hline Китай - Иран & - & $* *$ & $\mathrm{~T}$ & $* *$ & $* *$ & $* *$ \\
\hline Россия - Иран & - & $* *$ & $* *$ & $* *$ & - & $* *$ \\
\hline
\end{tabular}

Примечание. См. обозначения к табл. 1, 2. 
Можно видеть, что отношение к труду по значимым для индустрии 4.0 характеристикам существенным образом зависит от организационных условий в колледжах и от надежд студенток на будущее. Россиянки имеют самые высокие позитивные показатели. Их особенность состоит в зависимости показателя активности от удовольствия, которое девушки могут получить в трудовой/учебной деятельности $(\mathrm{r}=0.765, \mathrm{p} \leq 0.01)$. Это единственный значимый, но очень высокий коэффициент корреляции между показателями отношения к труду у девушекроссиянок, что объясняет их стремление к приоритету кланового компонента. Их активность растет в условиях хороших межличностных отношений, принятия, заботы, порождающих чувство субъективного благополучия. Настораживает отсутствие связи между показателями удовольствия и личностной вовлеченности в трудовой процесс. Это может свидетельствовать о приоритете общежитейской мотивации, снижающей качество трудовой и учебной деятельности. Такое предположение поддерживается данными о мнениях девушек. Они считают, что организационные условия предприятия, на которое они придут работать, практически не отличаются от условий их колледжей, за исключением более выраженного желаемого кланового компонента. Они не рассчитывают, а может быть, и не хотят трудиться на современном предприятии и поэтому не чувствуют необходимости в формировании готовности к работе в таких компаниях.

В иранских колледжах отношение студенток к учебе и труду самое негативное из сравниваемых групп респонденток. Превалируют значения негативных показателей. Иранки скорее пассивны, не вовлечены в работу и учебу и испытывают негативные чувства к ним. Это тоже объясняется суровостью организационных условий в колледжах и ожидаемой суровостью отношений и жесткостью требований на рабочих местах, а также отсутствием надежд на инновационное развитие компаний, которое так необходимо. Значимые положительные корреляционные связи прослеживаются между всеми основными показателями отношения к учебе/труду. Иранские девушки более активны, если они личностно вовлечены в учебный/трудовой процесс $(\mathrm{r}=0.365, \mathrm{p} \leq 0.01)$ и получают от него удовольствие $(\mathrm{r}=0.442, \mathrm{p} \leq 0.01)$, но они не вовлечены в данный процесс, в этом проблема их подготовки в колледже. Их зависимость от эмоциональных состояний слабее, чем у россиянок, тем не менее она есть, и это показывает значимость обеспечения их субъективного благополучия в образовательном процессе, что пока практически недостижимо.

Китаянок отличает сбалансированность показателей: они не слишком вовлечены в учебу/труд, не слишком активны и не слишком эмоционально удовлетворены. Но такие показатели представляются весьма адекватными образовательной и трудовой ситуациям. У молодых девушек есть, несомненно, еще немало значимых сфер деятельности. Тем не менее в их гармоничной ОК колледжей с высокой требовательностью, на которую они адекватно реагируют, с хорошими надеждами на будущую трудовую деятельность эти показатели выглядят вполне позитивно. Тем более что высокие положительные корреляционные связи основных показателей (между активностью и вовлеченностью, $\mathrm{r}=0.661, \mathrm{p} \leq 0.01$, между активностью и удовольствием, $\mathrm{r}=0.602, \mathrm{p} \leq 0.01$, между вовлеченностью и удовольствием, $\mathrm{r}=0.516, \mathrm{p} \leq 0.01)$ свидетельствуют о положительной сбалансированной мотивации к учебе и труду, поскольку в отличие от иранских 
и российских студенток они действительно субъективно благополучны в строгих, но не суровых организационных условиях своих колледжей и настроены на работу в инновационных компаниях.

Осуществив сравнительный анализ и обобщая полученные данные по странам, можно выделить целый ряд барьеров, препятствующих формированию готовности российских студенток индустриальных колледжей к работе в организационных условиях инновационных компаний. Во-первых, это информационные барьеры. Студентки не имеют ясных представлений о том, что такое инновационная компания, какими особенностями характеризуются ее организационные условия и какие требования она предъявляет сотрудникам.

Во-вторых, следует отметить организационно-культурные барьеры. Между ОК колледжа и ОК современного эффективного предприятия преемственность не прослеживается. В колледжах не уделяется достаточного внимания формированию характеристик, проявляющихся в психологическом облике и поведенческих моделях работника инновационной компании. Девушки ориентируются на удовольствие, которое они могут получить от того или иного занятия, что характерно для женского менталитета, хотя трудовая деятельность связана не только с эмоциональными, но и волевыми регуляторами (это заметно по характеристикам китаянок). Волевая регуляция поведения не просматривается, а это означает, что в колледжах не уделяется достаточного внимания формированию важнейшего качества профессионала - саморегуляции эмоциональных состояний и поведения.

Эмоциональные регуляторы важны, и их специфика, отмечаемая в колледжах, проявляется в третьем типе барьеров. Девушки испытывают субъективное неблагополучие, что, безусловно, снижает учебную и трудовую мотивацию. Они настроены на усиление клановой составляющей ОК в ущерб иерархическому и деловому компонентам. Поиск эмоциональной поддержки чреват несколькими негативными последствиями: снижением личной ответственности, пренебрежением регламентами, попытками решить рабочие проблемы на уровне межличностных договоренностей и уступок, подменой инновационности псевдоинновационностью, трудовой вовлеченности в учебную и трудовую деятельность активностью в сфере межличностных отношений, снижением участия в повышении квалификации и самообучении. Ценностная ориентация девушек на приоритет клановой составляющей в ОК не означает, что ей нужно следовать, слишком негативные последствия в общей подготовке специалиста имеют такие изменения организационных условий. Но и усиление иерархической составляющей не является выходом. Ситуация с отношением к учебе и труду в иранских колледжах показывает, насколько опасен крен, противоположный клановому, в организационных условиях.

Конструктивным решением является, по всей видимости, сбалансированная ОК, которую можно наблюдать в китайских колледжах. Это очень трудное для реализации решение, требующее внедрения специальных социализационных программ и подготовки педагогов, пока не готовых к эффективной упреждающей организационной социализации студенток, не имеющих ни мотивации, ни должных компетенций. Такие программы основаны на приоритете инновационных ценностей и балансе иерархических, клановых и деловых ценностей. 
Инновационные ценности - основа готовности к принятию технологических и управленческих инноваций, профессиональному и личностному развитию. Иерархические ценности являются предикторами соблюдения строгих регламентов и технологий производства. Клановые ценности дают необходимый уровень психологической защиты, снижают психологические издержки внедрения инноваций, способствуют становлению позитивного психологического климата. Требованиям преподавания и обучения по новым программам нельзя соответствовать без поведенческих компетенций в рамках делового (рыночного) контекста. Деловая этика сопряжена с высоким уровнем саморегуляции, обязательности, личной ответственности, способности работать в условиях внутренней конкуренции; готовностью к повышению квалификации и самообучению не только в настоящий момент, но и в условиях возможного перерыва в будущей трудовой деятельности в связи с беременностью и уходом за ребенком.

Такой подход вполне соответствует все более четко осознаваемой необходимости построения и в деловых организациях, и в образовательных учреждениях возрастных и гендерных экосистем, повышающих качество учебной и трудовой жизни и, следовательно, способствующих формированию перспективного человеческого капитала для новой экономики [Коростылева, 2019].

\section{Выводы}

1. Отношение к труду студенток индустриальных колледжей существенно зависит от экономической ситуации в стране, организационной культуры колледжей, адекватности представлений об организационной культуре современных эффективных компаний, желания работать в ординарных или инновационных компаниях и надежд на трудоустройство в них.

2. Наиболее благоприятной для становления мотивационной готовности к работе в условиях индустрии 4.0 является гармоничная организационная культура китайских колледжей. Субъективное неблагополучие и низкая трудовая мотивация иранских студенток - результат жестких условий иерархической организационной культуры и безнадежности трудовых перспектив.

3. В российских индустриальных колледжах формирование готовности девушек к работе в инновационных компаниях сдерживается целым комплексом организационно-культурных, информационных и регуляционных барьеров.

4. Для смягчения и преодоления выявленных проблем обучения студенток в индустриальных колледжах необходимы такие механизмы подготовки и повышения квалификации преподавательского корпуса и психологов для системы СПО, которые обеспечат упреждающую организационную социализацию для работы в организационных условиях современных предприятий.

\section{Библиографический список}

Внутских А. Ю., Комаров С. В. «Русская модель управления» и проблема производительности труда: философский анализ // Вестник Пермского университета. Сер.: Философия. Психология. Социология. 2019. Вып. 4. С. 473- 482.

Волков Д. В. Формирование новой модели труда и занятости на цифровой платформенной основе: (концептуальный аспект) // Экономические науки. 2020. № 190. С. $20-25$. 
Горобец А. В. Анализ конкурентоспособности российских высокотехнологичных компаний в современный период // Экономика и управление. 2015. Т. 122, № 1. C. $44-48$.

Дудырев Ф. Ф., Романова О. А., Травкин П. В. Трудоустройство выпускников системы среднего профессионального образования: все еще омут или уже брод // Вопросы образования. 2019. № 1. С. 109-136.

Завьялова Е., Алсуфьев А., Краковецкая И., Лицзюнь В., Ли Д. Развитие персонала в китайских инновационно-активных компаниях // Форсайт. 2018. Т. 12, № 3. C. $43-52$.

Захарова Л. Н., Шилова Л. Н., Гадбеджи 3., Чжу Лиучуан. Организационная культура индустриальных колледжей и предприятий России, Китая и Ирана в оценках студентов и преподавателей // Вопросы образования. 2020. № 3. С. 234-254.

Квачев В.Г., Юдина М. А. Индустрия 4.0: поражение работы или победа творческого труда // Государственное управление: электронный вестник. 2017. Октябрь. C. 140-158. URL: https://www.researchgate.net/publication/320923272_Industria 40_porazenie_raboty_ili_pobeda_tvorceskogo_truda_Industry_40_A_Loss_for_Labor_ or_a_Victory_for_Creative_Work (дата обращения: 12.11.2020).

Коростылева Н. Н. Формирование гендерной экосистемы современной организации: тенденции и перспективы // Женщина в российском обществе. 2019. № 3. С. 27-39.

Мамедова Н. Иранская экономика в условиях санкций // Мировое и национальное хозяйство. 2015. Т. 32, № 1. URL: https://mirec.mgimo.ru/2015-01/iranskaa-ekonomika-vusloviah-sankcij (дата обращения: 12.11.2020).

Нагимова Н. И., Фахретдинова М. А. Ключевые тренды развития «новой экономики»целевой ориентир подготовки профессиональных кадров // Среднее профессиональное образование. 2019. № 2. С. 11-16.

Парсонс T. О структуре социального действия. М.: Акад. проект, 2000. 880 с.

Савинская О. Б., Лебедева Н. В. Почему женщины уходят из STEM: роль стереотипов // Женщина в российском обществе. 2020. № 2. С. 62-75.

Brettel M., Chomik C., Flatten T. C. How organizational culture influences innovativeness, proactiveness, and risk-taking: fostering entrepreneurial orientation in SMEs // Small Business Management. 2015. Vol. 53, № 4. P. 868-885.

Cameron K.S., Quinn R.E. Diagnosing and Changing Organizational Culture Based on the Competing Values Framework. 3rd ed. San Francisco (CA): Jossey-Bass, 2011. 204 p.

Desmidt S., Prinzie A. Establishing a mission-based culture: analyzing the relation between intra-organizational socialization agents, mission valence, public service motivation, goal clarity and work impact // International Public Management Journal. 2019. Vol. 22, № 4. P. 664-690.

Ellis J., Fosdick B. K., Rasmussen C. Women 1.5 times more likely to leave STEM pipeline after calculus compared to men: lack of mathematical confidence a potential culprit // PLOS One. 2016. Vol. 7, № 11. P. 1-14.

Fetherston $M$. Information seeking and organizational socialization: a review and opportunities for anticipatory socialization research // Annals of the International Communication Association. 2017. Vol. 47, № 3-4. P. 258-277.

Global Innovation Index 2019 / ed. by S. Dutta, B. Lanvin, S. Wunsch-Vincent; Cornell SC Johnson College of Business. 12th ed. 2019. URL: https://www.globalinnovationindex.org/ gii-2019-report (дата обращения: 14.11.2020).

Spence J., Robbins A. Workaholism: definition, measurement and preliminary results // Journal of Personality Assessment. 1992. Vol. 58, № 1. C. 160-178.

Van Maanen J. People processing: strategies of organizational socialization // Organizational Dynamics. 1978. № 7. P. 18-36. 


\section{References}

Brettel, M., Chomik, C., Flatten, T.C. (2015) How organizational culture influences innovativeness, proactiveness, and risk-taking: fostering entrepreneurial orientation in SMEs, Small Business Management, vol. 53, no. 4, pp. 868-885.

Cameron, K. S., Quinn, R. E. (2011) Diagnosing and Changing Organizational Culture Based on the Competing Values Framework, 3rd ed., San Francisco, CA: Jossey-Bass.

Desmidt, S., Prinzie, A. (2019) Establishing a mission-based culture: analyzing the relation between intra-organizational socialization agents, mission valence, public service motivation, goal clarity and work impact, International Public Management Journal, vol. 22, no. 4, pp. 664-690.

Dudyrev, F. F., Romanova, O. A., Travkin, P. V. (2019) Trudoustroǐstvo vypusknikov sistemy srednego professional'nogo obrazovaniia: vsë eshchë omut ili uzhe brod [Employment of vocational graduates: still a slough or already a ford?], Voprosy obrazovaniia, no. 1, pp. 109-136.

Dutta, S., Lanvin, B., Wunsch-Vincent, S. (eds) (2019) Global Innovation Index 2019, Cornell SC Johnson College of Business, 12th ed., available from https://www.globalinnovationindex.org/gii-2019-report_(accessed 14.11.2020).

Ellis, J., Fosdick, B. K., Rasmussen, C. (2016) Women 1.5 times more likely to leave STEM pipeline after calculus compared to men: lack of mathematical confidence a potential culprit, PLOS One, vol. 7, no. 11, pp. 1-14.

Fetherston, M. (2017) Information seeking and organizational socialization: a review and opportunities for anticipatory socialization research, Annals of the International Communication Association, vol. 47, no. 3-4, pp. 258-277.

Gorobets, A. V. (2015) Analiz konkurentosposobnosti rossiǐkikh vysokotekhnologichnykh kompaniı̌ v sovremenny companies in the modern period], Ékonomika i upravlenie, vol. 122, no. 1, pp. 44-48.

Korostyleva, N. N. (2019) Formirovanie gendernoì èkosistemy sovremennol̆ organizatsii: tendentsii i perspektivy [The formation of modern organizations gender ecosystem: trends and prospects], Zhenshchina v rossiüskom obshchestve, no. 3, pp. 27-39.

Kvachev, V. G., Iudina, M. A. (2017) Industriia 4.0: porazhenie raboty ili pobeda tvorcheskogo truda [Industry 4.0: a loss for labor or a victory for creative work?], Gosudarstvennoe upravlenie: Ėlektronny $\check{1}$ vestnik, oktiabr', pp. 140—158, available from https://www.researchgate.net/publication/320923272_Industria_40_porazenie_raboty_ili_ pobeda_tvorceskogo_truda_Industry_40_A_Loss_for_Labor_or_a_Victory_for_Creative_ Work (accessed 12.11.2020).

Mamedova, N. (2015) Iranskaia èkonomika $v$ usloviiakh sanktsiǐ [Iranian economy under sanctions], Mirovoe i natsional'noe khoziăstvo, vol. 32, no. 1, available from https://mirec.mgimo.ru/2015-01/iranskaa-ekonomika-v-usloviah-sankcij (accessed 12.11.2020).

Nagimova, N. I., Fakhretdinova, M. A. (2019) Kliuchevye trendy razvitiia "novoĭ èkonomiki" - tselevoǐ orientir podgotovki professional'nykh kadrov [Key trends in the development of the 'new economy' - the target point of professional personnel training], Srednee professional'noe obrazovanie, no. 2, pp. 11-16.

Parsons, T. (2000) O strukture sotsial'nogo deistviia [The structure of social action], Moscow: Akademicheskii proekt.

Savinskaia, O. B., Lebedeva, N. V. (2020) Pochemu zhenshchiny ukhodiat iz STEM: rol' stereotipov [Why women leave STEM: the role of stereotypes], Zhenshchina $v$ rossiǔskom obshchestve, no. 2, pp. 62-75.

Spence, J., Robbins, A. (1992) Workaholism: definition, measurement and preliminary results, Journal of Personality Assessmen, vol. 58, no. 1, pp. 160-178. 
Van Maanen, J. (1979) People processing: strategies of organizational socialization, Organizational Dynamics, no. 7, pp. 18-36.

Vnutskikh, A. Iu., Komarov, S. V. (2019) "Russkaia model' upravleniia” i problema proizvoditel'nosti truda: filosofskiı̌ analiz [Russian management model and the problem of labor productivity: philosophical analysis], Vestnik Permskogo universiteta, seriia Filosofiia. Psikhologiia. Sotsiologiia, iss. 4, pp. 473- 482.

Volkov, D. V. (2020) Formirovanie novoĭ modeli truda i zaniatosti na tsifrovoř platformennoř osnove: (Kontseptual'nyı̌ aspekt) [Formation of a new model of labor and employment on a digital platform: (Conceptual aspect)], Ėkonomicheskie nauki, no. 190, pp. 20-25.

Zakharova, L. N., Shilova, L. N., Gadbedzhi, Z., Chzhu Liuchuan (2020) Organizatsionnaia kul'tura industrial'nykh kolledzheĭ i predpriiatǐ̌ Rossii, Kitaia i Irana v otsenkakh studentov i prepodavateler [Organizational cultures of vocational schools and enterprises in Russia, China and Iran as perceived by students and teachers], Voprosy obrazovaniia, no. 3, pp. 234-254.

Zav'ialova, E., Alsuf'ev, A., Krakovetskaia, I., Litsziun', V., Li, D. (2018) Razvitie personala $\mathrm{v}$ kită̌skikh innovatsionno-aktivnykh kompaniiakh [Personnel development in Chinese innovation-active companies], Forsăt, vol. 12 , no. 3, pp. 43-52.

Авторы выражают благодарность магистру психологии Чжу Лиучуан, оказавшей неоценимую помощь в сборе данных в КНР.

Статья поступила 12.12.2020 2.

\section{Информация об авторах / Information about the authors}

Захарова Людмила Николаевна - доктор психологических наук, профессор, заведующая кафедрой психологии управления, Национальный исследовательский Нижегородский государственный университет им. Н. И. Лобачевского, г. Нижний Новгород, Россия, zlnnnov@mail.ru (Dr. Sc. (Psychology), Professor, Head of the Department of Psychology of Managment, National Research Lobachevsky State University of Nizhny Novgorod, Nizhny Novgorod, Russian Federation).

Саралиева Зарэтхан Хаджи-Мурзаевна - доктор исторических наук, профессор кафедры общей социологии и социальной работы, Национальный исследовательский Нижегородский государственный университет им. Н. И. Лобачевского, г. Нижний Новгород, Россия, zara@fsn.unn.ru (Dr. Sc. (History), Professor at the Department of General Sociology and Social Work, National Research Lobachevsky State University of Nizhny Novgorod, Nizhny Novgorod, Russian Federation).

Гадбеджи Захра - аспирантка кафедры психологии управления, Национальный исследовательский Нижегородский государственный университет им. Н. И. Лобачевского, г. Нижний Новгород, Россия, z.ghadbeigi@gmail.com (Post-graduate student at the Department of Psychology of Managment, National Research Lobachevsky State University of Nizhny Novgorod, Nizhny Novgorod, Russian Federation). 